\title{
A GOVERNANÇA DE TIC NO PROCESSO DE MODERNIZAÇÃO DAS SERVENTIAS EXTRAJUDICIAIS DO BRASIL
}

OMar OMar

Doutorando em Engenharia do Conhecimento pela Universidade Federal de Santa Catarina (UFSC). Professor Assistente na Universidade do Estado de Santa Catarina (UDESC) e membro do LABGES - Laboratório de tecnologias de Gestão da UDESC/ESAG. E-mail: omarx02@gmail.com

Carlos Roberto De Rolt

Doutor em Engenharia de Produção pela Universidade Federal de Santa Catarina (UFSC). Professor Associado da Universidade do Estado de Santa Catarina (UDESC) e coordenador do LABGES. E-mail: crderolt@gmail.com

\section{Resumo}

As serventias extrajudiciais do Brasil, responsáveis pelos serviços públicos delegados, incluindo os notariais e de registro, estão envolvidos em um processo coletivo de modernização, de escopo nacional, cujos principais objetivos incluem a prestação dos seus serviços de forma digital ou eletrônica. O processo está fortemente alicerçado na utilização de tecnologias da informação e comunicação (TIC) e este artigo, portanto, busca compreender e avaliar a gestão e governança de TIC do processo de modernização em curso. Para isso, foi realizada uma pesquisa semiestruturada, baseada nos frameworks de melhores práticas de governança e gestão de TIC ITIL e COBIT, junto às entidades representativas das serventias extrajudiciais envolvidas no processo de modernização. Dentre os principais resultados encontrados pode-se citar o baixo nível de maturidade da gestáo de TIC envolvida no processo e a identificação de processos chave de TIC, essenciais ao sucesso do processo de modernização.

\section{Palavras-chave}

E-gov; Serviços públicos delegados; Serventias extrajudiciais; Governança de TIC; Serviços compartilhados; Assimetria jurídica.

\section{Abstract}

Brazil's nationwide public delegate services' offices are involved in a collective modernization process that has among its main objectives the digital/electronic delivery of 
its services, therefore simplifying and improving the effectiveness and efficiency of the services provision. The process relies heavily on Information and Communication Technologies (ICT) and therefore this article seeks to understand the process' ICT governance and management current state and needs. To achieve this goal, a semi structured survey, based on ICT best practices frameworks ITIL and COBIT, was carried out among the public delegate services offices' representative entities involved in the modernization process. Main findings include the assessment of a low maturity level of the management of ICT involved in the process and the identification of key ICT processes associated with the current handling of ICT governance and management. Future research can focus on the production of an ICT governance and management model tailored to meet the modernization process' needs.

\section{Key words}

ICT governance; Shared services; E-gov; Public services; Service delivery.

\section{Introdução}

As TIC redefiniram os níveis de produtividade, velocidade e eficiência no mundo organizacional contemporâneo (PORTER, 1997; PORTER, 1998). E, apesar do que afirma o paradoxo de produtividade (BRYNJOLFSSON; MCAFEE, 2014) sobre os resultados práticos do emprego de TIC, pode-se afirmar que estas são onipresentes e seu uso é intensivo em organizaçóes de todos os tipos, tamanhos ou indústrias (BRYNJOLFSSON; MCAFEE, 2014).

As serventias extrajudiciais brasileiras, responsáveis pela prestação dos serviços notariais e de registro no Brasil, náo fogem à regra, e têm intensificado o emprego de TIC com o propósito de modernizar suas operaçóes e a entrega de serviços, ajustando e preparando, dessa forma, toda a indústria à nova realidade econômica e social, caracterizada pela inovação e intensa competição (SERBENA, 2013; SARTURI e COSTA, 2012; COSTA, 2009; COSTA et al. 2008)

No Brasil, as serventias extrajudiciais e os cartórios notariais e de registro são responsáveis pelo provimento à sociedade de confiança necessária à realização de transaçôes comerciais e de troca em todos os níveis (BAGATIN; DALLA COSTA, 2012). São as serventias que certificam que toda sorte de documentos (como contratos, cópias, certificados, documentos legais, rubricas ou qualquer documento formal) são autênticos, íntegros, e confiáveis em todo o território nacional. As serventias são também responsáveis pela custodia e publicidade desses documentos (tornando-os públicos perante à sociedade) quando assim requisitado. Na prática, as serventias são uma extensão do governo brasileiro, através dos quais o governo alcança, conecta-se e comunica-se com seus cidadãos, e provê os serviços necessários à manutenção de um ambiente social e de negócios estável e confiável (BAGATIN; DALLA COSTA, 2012). 
A importância das serventias à sociedade brasileira é, portanto, vital. É através das serventias e dos cartórios públicos de serviços delegados que o cidadão e as pessoas jurídicas estabelecem um relacionamento entre si e com o Estado, que, por sua vez, emprega os dados e informaçáo coletada, produzida e armazenada pelas serventias para criar ou aperfeiçoar políticas públicas em todas as esferas de governo (política, econômica, fiscal e social) (DOS SANTOS ET AL, 2014; BAGATIN; DALLA COSTA, 2012).

A melhoria contínua e continuada e modernização das operaçóes das serventias, portanto, é chave não somente para o seu próprio avanço e excelência, mas também para o progresso econômico e social de toda a sociedade brasileira (DOS SANTOS ET AL, 2014). As serventias extrajudiciais brasileiras estão cientes dessa realidade e, através das suas entidades representativas, realizam um conjunto de açôes e medidas coordenadas com o propósito da melhoria e modernização de seus serviços, o que constitui o processo nacional de modernização das serventias extrajudiciais.

O status quo corrente do processo de modernização, contudo, não possui uma padronização dos processos de ferramentas de TIC envolvidas, reflexo da falta de padronização do processo regulatório dos próprios serviços prestados, que difere de estado para estado no contexto brasileiro. A falta de padronizaçáo produz um excesso de burocracia e não agrega à cadeia de valor dos serviços notariais e de registro brasileiros.

Para mitigar esse cenário e nortear o aprimoramento e desenvolvimento da prestação desses serviços, o processo de modernizaçáo avança criando centrais de serviços eletrônicos compartilhados (CSEC), baseadas no conceito de serviços compartilhados. As CSEC integram os diferentes agentes envolvidos no processo de modernização (As próprias serventias e cartórios espalhadas pelo território nacional e respectivas entidades representativas, fornecedores, clientes e cidadáos, o Estado e as diferentes esferas de governo envolvidas, agências regulatórias e centros acadêmicos de pesquisa) com o emprego da teoria de organizaçóes virtuais como modelo de gestão e o uso intensivo de TIC como ferramenta de implementação (COSTA, 2009; DE ROLT; DIAS; COSTA, 2008)

O uso intensivo e níveis elevados de dependência das TIC resulta em elevada complexidade e desafios em termos de gestão, continuidade na prestação dos serviços e tolerância a falhas (DOS SANTOS ET AL, 2014). Conjuntos de melhores práticas para gestão e governança de TIC como ITIL e COBIT foram concebidos para mitigar os riscos e complexidade associados à esse cenário e são, hoje, extensamente utilizados por virtualmente qualquer organização com operações de TIC (ISACA, 2015).

Os conjuntos de melhores práticas são o resultado de uma combinação com experiência empírica de gestores de TIC do mundo real e esforços científicos e acadêmicos de pesquisadores e especialistas renomados e organizaçóes internacionais de nível mundial, e proveem, em função disso, um conjunto de medidas e conhecimentos voltados à governança e gestão de TIC, que têm como propósito nortear as estratégias e operaçóes de 
governança e gestão de TIC (políticas, processos e tomadas de decisão), tanto em nível de formulação, implantação quanto operação.

Esta pesquisa utilizou os frameworks de melhores práticas ITIL e COBIT para construir e conduzir surveys e entrevistas semi estruturadas junto às entidades representativas das serventias extrajudiciais que capitaneiam o processo coletivo de modernização dos serviços públicos delegados no Brasil, assim como os gestores das CSEC. O objetivo do estudo foi determinar o estado atual e nível de maturidade das práticas de gestão e governança de TIC e sua adequação às demandas e necessidades do processo de modernização.

Compreender o status corrente e assessorar o nível de maturidade da gestão de TIC do processo de modernização é de suma importância e determinante para o sucesso do próprio processo de modernização, dada a importância e intenso uso das TIC para e pelo processo como um todo.

\section{O Processo de Modernização, as Organizações Virtuais e a CSEC}

$\mathrm{O}$ modelo de gestáo adotado pelo processo de modernização, que culminou com a criação da CSEC - Central de Serviços Eletrônicos Compartilhados - considera que a complementariedade de competências entre os diversos atores e organizaçóes envolvidas possibilita o desenvolvimento de um conjunto de açóes, processos e procedimentos de forma coordenada e integrada, na direção da modernização dos serviços prestados pelas serventias extrajudiciais e serviços notariais (COSTA, 2009).

O esforço em termos de cooperação visa a produção e utilização de novas ferramentas tecnológicas, aplicativos, e técnicas de gestão, através do emprego intensivo de TIC, com o propósito de atender as demandas da sociedade brasileira no tange a publicação e publicidade de informação, serviços de registro e serviços notariais. Uma representação gráfica do modelo de gestão proposto pelo e para o processo de modernização pode ser vista na figura 01 .

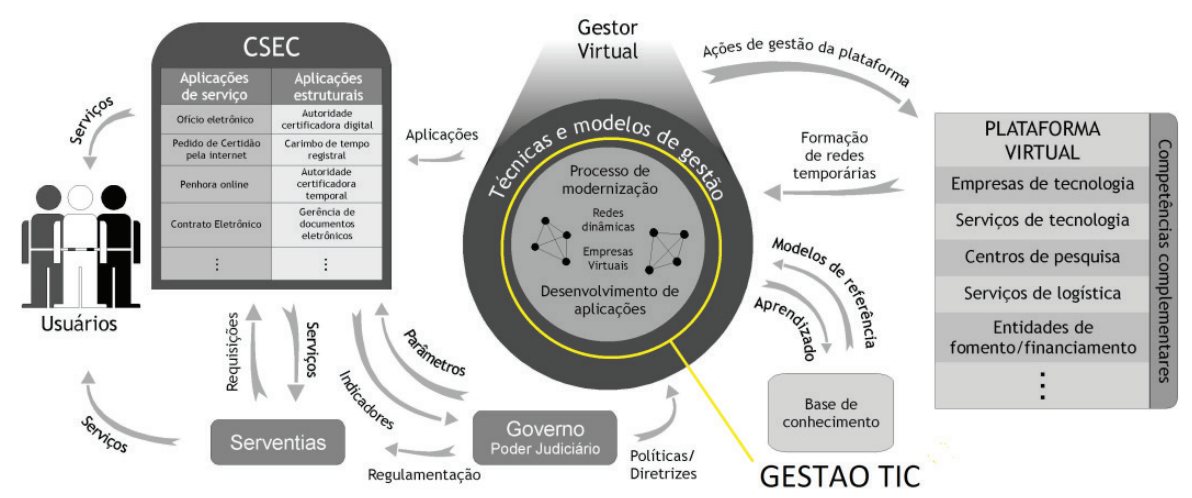

Figura 01 - O modelo de gestão do processo de modernização 
O modelo está alicerçado na teoria de organizaçóes virtuais proposta por Frank (CARMINHA-MATOS ET AL, 2005) como modelo de gestão para a cooperação entre as entidades representativas, as próprias serventias extrajudiciais, fornecedores e clientes e usuários sobre os quais o processo de modernização, e a central eletrônica de serviços compartilhados, são construídos. A teoria das organizações virtuais propóe os conceitos de plataforma virtual: um conjunto de entidades/partes/empresas com competências complementares); o net-broker: uma figura central que coordena o fluxo de trabalho entre os atores envolvidos na organização virtual; e a própria organização virtual: uma entidade temporária formada por um subconjunto da plataforma virtual com objetivos definidos que devem ser alcançados empregando as competências dos atores selecionados através da coordenação e direção do net-broker. Na figura 01, estes componentes estão representados no contexto do desenvolvimento de aplicações pela CSEC.

A CSEC é, portanto, a organização virtual de facto que emerge do modelo de gestão para materializar o processo de modernização na forma de serviços eletrônicos compartilhados, providos pelas serventias extrajudiciais e cartórios de registro e notariais com o uso de ferramentas de TIC desenvolvidas pela organização virtual, prestados à sociedade. Dentre esses pode-se citar a autenticação e reconhecimento de documentos e firmas, a conferência de publicidade e custódia, validação de contratos, emissão de certificados e documentos oficiais, dentre outros serviços (BAGATIN; DALLA COSTA, 2012).

A plataforma virtual consiste em uma rede de empresas individuais que possuem acordos de cooperação pré-estabelecidos, ativados sob requisição do net-broker através do emprego de ferramentas de TIC e softwares que conectam as partes e proveem os recursos para realizar a entrega de serviços pela CSEC (organização virtual). De modo geral, partes e atores da plataforma virtual são selecionados para desenvolver novos softwares estruturantes e de serviços, utilizados pela CSEC. Nesse contexto, os membros da plataforma virtual agem de modo independente e em muitos casos distribuídos geograficamente, embora estejam conectados à plataforma através dos mecanismos de integração, e com base em objetivos comuns aderentes ao processo de modernização.

O net-broker é o representante oficial e legítimo dos componentes da plataforma virtual, e tem como responsabilidades gerenciar os esforços de modernização, o zelo pela manutenção do nível de serviço dos serviços prestados, e o desenvolvimento e implantação de novos serviços. Nesse sentido, o net-broker busca promover novas oportunidades no contexto da plataforma virtual e identificar as companhias com as respectivas competências necessárias, empregando as tecnologias de gestão das organizaçóes virtuais. $\mathrm{O}$ net-broker, ainda, mantém uma base de conhecimento sobre as ferramentas de gestão e tecnologias empregadas pelo processo de modernização, é responsável pelos contratos jurídicos e modelos de propriedade intelectual utilizados pelos atores da organização virtual (CSEC). A coordenação geral do processo de inovação e a implantação dos resultados na forma de novos serviços prestados, suportados por software e ferramentas de 
TIC relacionadas, pela CSEC, com o objetivo final de aprimorar a eficiência e a melhoria continua dos serviços prestados à população e sociedade complementa o conjunto de atribuições do net-broker.

Organizaçóes virtuais são redes de empresas compostas por atores selecionadas a partir de uma plataforma virtual, que trabalham em conjunto, de forma coordenada, para satisfazer objetivos pré-definidos (CAMARINHA-MATOS ET AL, 2005), e produzem, no contexto do processo de modernização, artefatos de software que pode ser estruturante: realiza funçóes internas da CSEC, como comunicação, infraestrutura e software de base; ou de aplicação: voltado à prestação de serviços ao cidadão, e à sociedade, pelos cartórios notariais ou de registro correspondentes, com a coordenação e o suporte do net-broker. $\mathrm{O}$ ciclo de vida de uma dada organização virtual é determinado pelo cronograma do projeto e o ciclo de desenvolvimento. Como a cooperaçáo encontra-se no cerne do modelo de gestáo proposto, os desafios da modernização, em contraste com a velocidade e agilidade exigidos para o desenvolvimento e implantação de novas aplicaçôes e, consequentemente, serviços, demandam que o net-broker busque competências externas, principalmente nos campos técnico, de infraestrutura, desenvolvimento de software e novas tecnologias.

A CSEC oferece um conjunto de serviços que requerem infraestrutura de TIC, recursos humanos, softwares de gestão e aplicativos, conhecimento, dentre outros requisitos não encontrados internamente, no contexto interno da cooperação entre as serventias. Por isso, o desenvolvimento e provisão de serviços são essenciais não somente à entrega final e prestação de serviços à sociedade, como também ao próprio processo de modernização e a plataforma como um todo, compreendendo os cartórios, entidades representativas, fornecedores e até mesmo os clientes.

O governo através do sistema judiciário e respectivas instituiçóes desempenha, também, um importante papel no processo de modernização, estabelecendo os parâmetros, requerimentos e regras sob as quais as novas aplicaçóes e serviços devem ser desenvolvidos, reduzindo dessa forma a assimetria normativa, o que resulta em maior padronização dos processos e regras de negócios e, em última instância, dos próprios serviços prestados.

O ambiente complexo onde o processo de modernização está sendo desenvolvido e implementado, e o uso intensivo de TIC para implementar as organizaçóes virtuais e a entrega dos serviços de forma eletrônica, requerem um nível elevado de governança e de gestão das TIC envolvidas no processo de modernização, e esta pesquisa, portanto, buscou identificar as necessidades em termos de governança e gestão de TIC e assessorar o seu nível de maturidade, com base nos conjuntos de melhores práticas.

\section{Governança e Gestão de TIC}

Rowlands, Haes e Grembergen (2014) comentam o fato de o termo governança de TI (ou de TIC) possuir várias definiçóes. As diversas definiçóes para o termo demonstram 
a falta de um entendimento comum sobre a governança de TIC. Esta seção, portanto, visa esclarecer este importante conceito para a pesquisa, expondo as ideias dos principais autores sobre o tema.

A relevância da governança de TIC para as organizaçóes pode ser explicada pelo advento da lei Sarbanes-Oxley e do acordo de Basiléia II, pelo amadurecimento dos frameworks de controle, como o COSO, e pela consolidação das práticas de governança corporativa nas organizaçóes. (LAHTI; PETERSON, 2005; HARDY, 2006)

De forma sintética, e a partir de uma analogia com a Governança Corporativa, que como mencionado anteriormente visa o controle e direção da organização (ISACA, 2014), pode-se afirmar que a Governança de TI visa o controle e direção da TI junto à organização (ROWLANDS; DE HAES; GREMBERGEN, 2014; DE HAES; GREMBERGEN, 2004). De fato, Grembergen et al (2004), afirma que a governança de TI é a "capacidade organizacional exercida pela direção, gestão executiva e gestão de TI com o propósito de controlar a formulação e implementação de estratégicas de TI e assim garantir a fusão da TI com o negócio”.

Dessa forma, ao considerar a TI como parte integrante do negócio (DE HAES ET AL, 2013; ITGI, 2012), torna-se evidente a necessidade do alinhamento da sua governança à corporativa. Para esses autores, o principal objetivo da governança de TI consiste em alinhar a TI aos requisitos do negócio e objetivos da organização. O ITGI (2012) define a Governança de TI como uma estrutura de processos que se relacionam entre si, com os recursos de TI e com os requisitos de negócio para dirigir e controlar a empresa, a fim de atingir suas metas e objetivos enquanto considera os riscos contra os investimentos em TI e seus processos. Para ISACA (2015), são os requisitos de negócio que definem os parâmetros em termos de resultado que balizam os objetivos de controle de TI a serem estabelecidos.

O controle de TIC, por sua vez, compóe-se de práticas, procedimentos e políticas que se baseiam em métricas e indicadores de desempenho pré-estabelecidos, visando ao mesmo tempo que os objetivos do negócio sejam atingidos e que eventos náo desejáveis sejam prevenidos ou detectados e corrigidos (ITGI, 2012). Dessa forma, a utilização de conjuntos de melhores práticas facilita a implantação de controles de TIC eficientes (LAHTI; PETERSON, 2005; DE HAES; GREMBERGEN, 2004; ROWLANDS; DE HAES; GREMBERGEN, 2014). De fato, Lahti e Peterson (2005) indicam o COBIT como a principal ferramenta para implantar os controles exigidos pela lei SOX. De forma semelhante, Goeken e Alter (2008) utilizaram o COBIT como método para criar um modelo de avaliação de outros frameworks de implantação de governança de TIC.

A própria definição do COBIT, segundo De Haes et. al. (2013), enfatiza o seu foco no controle, afirmando que o COBIT constitui um completo framework para implantar a governança de TIC nas organizaçóes (Veja a seção COBIT da fundamentação teórica 
dessa dissertação para maiores detalhes). Goeken e Alter (2008) sugerem uma abordagem semelhante ao defender a implantação da governança de TIC utilizando o COBIT.

Embora amplamente reconhecido como importante no meio acadêmico e corporativo, o foco exclusivo no controle, e consequentemente no COBIT, é tido como insuficiente, por si só, para implantar a governança de TIC nas organizaçôes. (STEENBERGEN ET AL, 2007)

Steenberg et al (2007) afirma que é preciso complementar o conhecimento de frameworks, como o COBIT, com o conhecimento oferecido por outros frameworks, assim como pesquisas acadêmicas, a fim de obter um suporte e visão holísticos para a governança e também gestão de TIC.

Para ITGI, 2008 e De Haes e Grembergen (2004), "há uma clara diferença entre governança de TIC e gestão de TIC [...] a gestão de TIC envolve o eficaz e eficiente suprimento de produtos e serviços de TIC, assim como a gestão das operaçóes de TIC. Enquanto a governança de TIC abrange um conceito maior e mais amplo, focado em governar e transformar a TIC para atender as demandas do negócio e seus clientes, tanto no presente quanto no futuro". (DE HAES; GREMBERGEN, 2004)

Torna-se evidente, a partir do exposto acima, que a governança de TIC compreende, além do seu controle (COBIT), também a sua gestão, o que, portanto, demanda a utilização de outros frameworks na sua implantação.

A ITIL é reconhecida como o padrão de facto de gerenciamento de TIC do mercado (ITGI; OGC, 2008), e possui um foco maior na implementação e gestão de serviços

de TIC, enquanto o COBIT possui um foco mais voltado ao controle e governança em níveis mais estratégicos (ITGI, 2012; ISACA, 2015).

Combinar ambos na implantação de governança de TIC, portanto, emerge naturalmente a partir do estudo da literatura (acadêmica e corporativa) existente.

\section{Metodologia}

O universo de pesquisa desse estudo compreendeu as entidades representativas envolvidas no processo de modernização das serventias extrajudiciais, as próprias serventias extrajudiciais, assim como o net-broker da CSEC. Dados qualitativos e quantitativos foram coletados empregando dois instrumentos: entrevistas semi-estruturadas realizadas junto às entidades representativas e o net-broker da CSEC; e um questionário eletrônico distribuído aos gestores das serventias extrajudiciais.

Tanto o questionário quanto o roteiro das entrevistas foram construídos de acordo com os frameworks de melhores práticas ITIL e COBIT, e buscaram cobrir os domínios 
de gestão de riscos de projetos de TIC, operaçóes de TIC e a gestão de infraestrutura de TIC, com as respectivas necessidades em termos de recursos e capacidades.

As entrevistas buscaram, ainda, coletar a percepção do entrevistado no que diz respeito às operaçóes de TIC da CSEC e entidades representativas; identificar o que foi realizado e o que está sendo feito em termos de gestão e governança de TIC; e identificar desafios e necessidades em termos de governança e gestão de TIC no contexto do processo de modernização.

Os resultados obtidos foram agrupados em dois conjuntos: um que endereçou as necessidades e delimitou as prioridades em termos de TIC do processo de modernização, compreendendo as operaçóes e processos correntes; e outro que buscou determinar o nível de maturidade dos processos de governança e gestão de TIC correntes.

\section{Resultados}

Com relação às necessidades do processo em termos de TIC, os gestores foram solicitados a priorizar os campos e áreas de atuação no contexto de governança e gestão de TIC, como pode ser verificado na figura 02 .

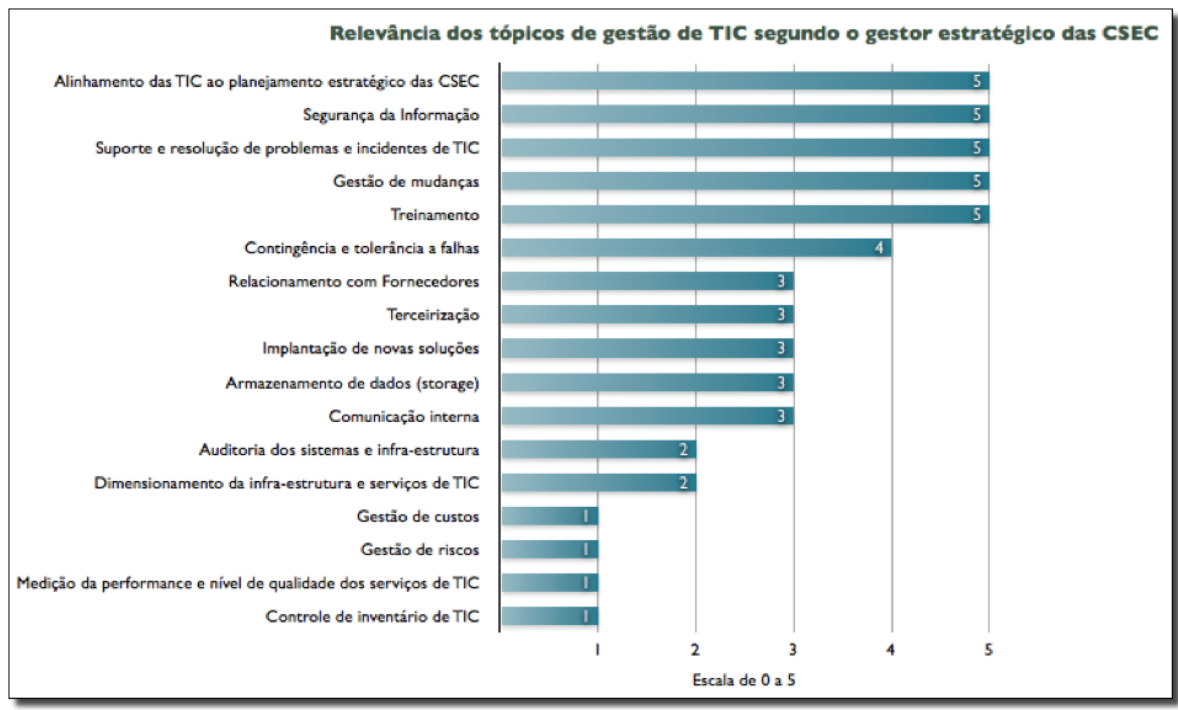

Figura 02 - Prioridade do campos de governança e gestâo de TIC segundo os gestores envolvidos no processo de modernização

Embora à primeira vista todos os campos pareçam igualmente relevantes, os gestores entrevistados foram instruídos a priorizar alguns campos em detrimento de outros, levando em consideração o que é essencial ao sucesso e correto funcionamento da CSEC. 
Os gestores consideraram o alinhamento entre TIC e as necessidades do negócio (CSEC) como um dos itens mais fundamentais e de maior relevância para uma implementação satisfatória da CSEC. Como a natureza das informaçóes providas pelas serventias extrajudiciais é sensível e crítica à própria prestação do serviço, os gestores elegeram a segurança da informação como de alta prioridade. Treinamento, gestáo de mudanças e suporte e entrega de serviços completam a lista de prioridades máximas, em função de o processo de modernização e a própria CSEC ainda demandarem uma série de ajustes e configuraçóes, devido à inovação envolvida no processo e também à novidade em termos de ferramentas para a prestação de serviços, onde as serventias ainda estão aprendendo, e adaptando-se, sobre como utilizar explorar as novas possibilidades e serviços proporcionados pela CSEC.

Como já mencionado, as serventias públicas delegadas do Brasil entregam serviços que lidam com a entrega e provisão de informaçôes que regulam e regulamentam a condução de negócios e possibilitam o estabelecimento de uma relação entre o estado e seus cidadãos, e desses entre si. Exemplos incluem a validação de contratos; publicidade de informaçôes e documentos; guarda de contratos e documentos; escrituras públicas de propriedade; autenticaçáo de documentos e assinaturas; dentre outros. Dessa forma, a gestão e manipulação da informação é, também, essencial à implementação e o funcionamento da CSEC e, por isso, as entrevistas basearam-se nos critérios de informação empregados pelo conjunto de melhores práticas COBIT, de modo a classificar por ordem de importância os critérios de informação, como pode ser visto na figura 03.

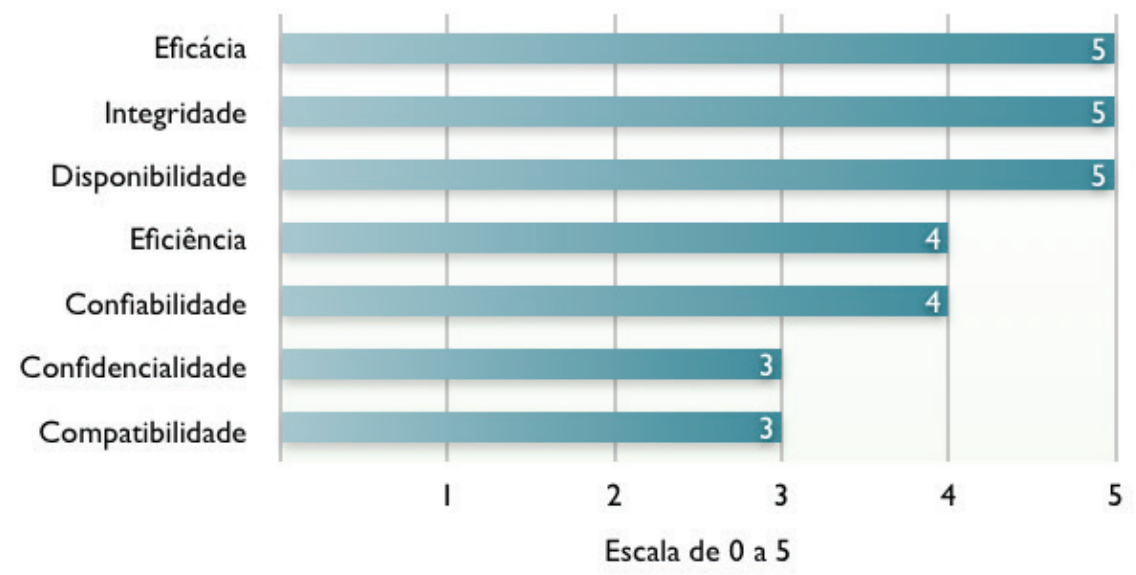

Figura 03 - Relevância dos critérios de informação definidos pelo COBIT de acordo com os gestores entrevistados

De acordo com a figura 03, pode-se perceber que a eficácia, a integridade e a disponibilidade das informaçóes no contexto da CSEC constituem os aspectos fundamentais a 
considerar, de modo que os processos de TIC envolvidos com a entrega de serviços devem assegurar que a informação esteja dotada desses critérios. Eficiência e confiabilidade sucedem em termos de importância, em detrimento da confidencialidade e compatibilidade.

As prioridades definidas pelos gestores revelam uma preocupação com a entrega de serviço, provavelmente em função do grande grau de inovação empregada na entrega eletrônica de serviços prestados historicamente de modo manual. $\mathrm{O}$ foco dos gestores, desse modo e ao menos até a disseminação e consolidação da utilização da CSEC, esta voltado à critérios como a integridade e disponibilidade e outros critérios de informação necessários a uma satisfatória entrega de serviços.

Além da relevância dos tópicos de governança e gestão de TIC e dos critérios de informação, o estudo buscou mensurar a nível de maturidade dos tópicos de gestão de TIC na percepção dos gestores entrevistados. Para isso, foi empregado o modelo de maturidade de processos de TIC definido pelo COBIT, que prevê seis níveis de maturidade (de 0 para processo inexistente a 5 para processo otimizado), conforme consta na figura 04 .

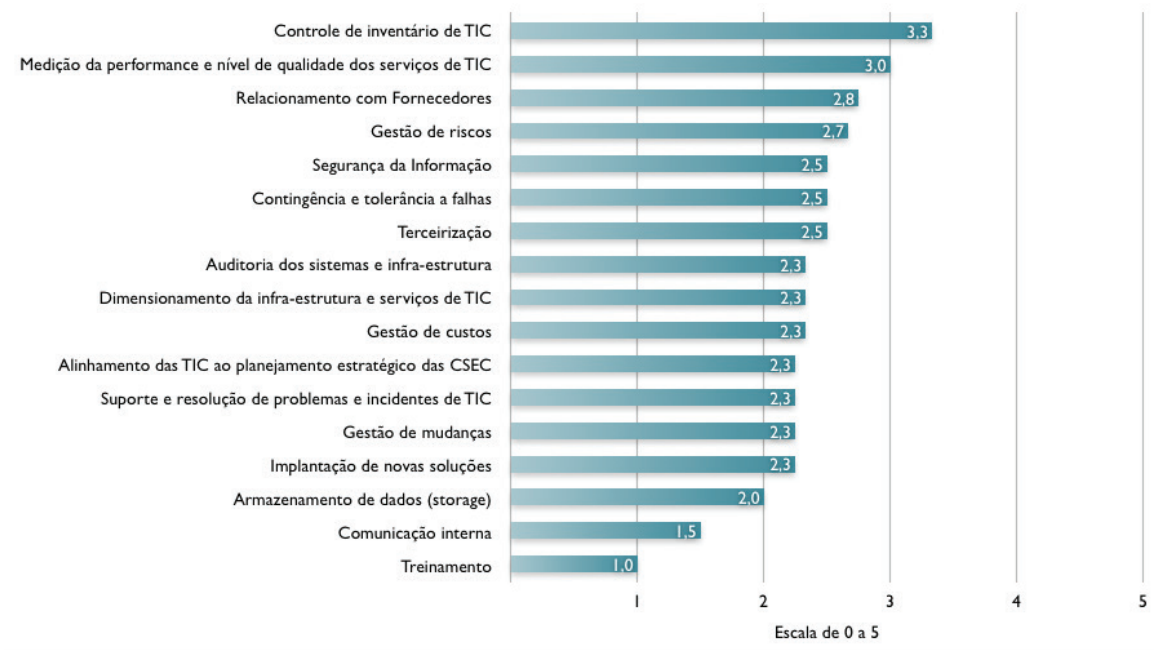

Figura 04 - maturidade dos tópicos de gestão de TIC na CSEC na percepção dos gestores entrevistados

A análise da figura 04 permite inferir que, apesar de existirem dois tópicos com nível de maturidade três ou superior, que é a métrica definida pelo COBIT para considerar de fato que há um ou mais processos definidos (Controle de inventário de TIC com 3,3 e Medição da performance e nível de qualidade dos serviços de TIC com 3,0), o nível de maturidade da governança e gestáo de TIC de modo geral no contexto da CSEC é baixo.

Ademais, os tópicos com nível de maturidade minimamente satisfatório (3 ou superior) referem-se à infraestrutura (controle de inventário) e a medição de performance, 
distantes dos tópicos necessários ao provimento de serviços em si, envolvidos com a entrega de serviços eletrônicos pela CSEC.

Chama a atenção, especialmente, o baixo nível de maturidade de tópicos considerados fundamentais, e que receberam a maior atribuição em termos de prioridade por parte dos gestores entrevistados. Dentre esses, destaca-se o nível de maturidade dos tópicos: treinamento (nível 1); alinhamento das TIC ao planejamento estratégico da CSEC (nível 2,3); gestão de mudanças (nível 2,3); segurança da informação (nível 2,5); e suporte e resoluçáo de problemas e incidentes de TIC (nível 2,5), todos definidos como prioridade máxima (5) para a governança e gestão de TIC do processo de modernização.

\section{Conclusões}

Com base nos resultados da pesquisa, pode-se concluir que apesar do intenso uso de tecnologias da informação e comunicação e da dependência da CSEC dessas, o processo de modernização das serventias extrajudiciais e dos serviços por elas prestados, como um todo, possui um baixo nível de maturidade no diz respeito a governança e gestão de TIC, com muitas atividades de TIC no contexto do processo de modernização sendo realizadas de modo fragmentado, sem processos estruturados ou definidos. Por outro lado, percebese que os gestores envolvidos no processo de modernização reconhecem a necessidade da otimização da TIC empregada e o uso de processos definidos com mecanismos de governança de TIC que aumentariam a robustez e nível de confiabilidade e, em última instancia, sustentabilidade e perenidade da CSEC.

O estudo, ainda, lança luz sobre, e detalha as práticas, modo de funcionamento e organização do estado brasileiro no que tange a estrutura da informação, e prestação de serviços de registro e também notariais no âmbito das leis e sociedade brasileira, e detalha os esforços de modernização, incluindo o modelo de gestão, a estrutura e a organização envolvidos no processo nacional de modernização desses serviços, que culminou com a criação da CSEC.

Nesse contexto, deve-se registrar como principal percepção a necessidade de empreender esforços na direção da redução da assimetria normativa que rege os serviços notariais e de registro do Brasil, uma meta do próprio estado brasileiro. Tal padronização permitirá aumentar o nível de integração entre os sistemas computacionais e bancos de dados, um pré-requisito para que os serviços públicos delegados passem a agregar valor ao sistema econômico e sociedade como um todo.

Como recomendação para estudos futuros, a pesquisa torna evidente a necessidade do desenvolvimento de uma proposta para um modelo de gestão que permita aos diversos setores agir para diminuir a assimetria normativa. Adiciona-se a necessidade paralela de 
implantar um modelo de governança e gestão de TIC que norteie o curso do processo de modernização e a implementação da CSEC e novos serviços eletrônicos, para padronizar e uniformizar a prestação dos serviços prestados pelas serventias extrajudiciais nas diferentes esferas (pessoa física; pessoa jurídica; sistema judiciário; e instituições públicas e privadas).

\section{Referências}

BAGATIN, Kellen Medeiros; DALLA COSTA, Armando. Cartórios como empresas de serviços publicos ocupadas via concurso. Revista Organização Sistêmica, v. 2, n. 1, p. 82-101, 2012.

BRYNJOLFSSON, Erik; MCAFEE, Andrew. The second machine age: work, progress, and prosperity in a time of brilliant technologies. WW Norton \& Company, 2014.

CAMARINHA-MATOS, Luis M.; AFSARMANESH, Hamideh; OLLUS, Marin. Virtual Organizations: systems and practices. ISBN 978-0-387-23755-8. Springer, 2005.

COSTA, T. Modernizaçáo dos serviços de registro público no Brasil: Proposta da averbação eletrônica da penhora de imóveis. 2009. 133f. Dissertação. (Mestrado Profissional em Administração), Universidade do Estado de Santa Catarina. Florianópolis.

COSTA, T.; DE ROLT, C. R.; DIAS, J. S. O conceito de serviços compartilhados como fundamento para a inovaçáo dos serviços públicos delegados no Brasil. In: Simpósio de Gestão da Inovação Tecnológica, 25, 2008, Brasília. Anais... Brasília, 2008.

DE HAES, Steven; VAN GREMBERGEN, Wim; DEBRECENY, Roger S. COBIT 5 and enterprise governance of information technology: Building blocks and research opportunities. Journal of Information Systems, v. 27, n. 1, p. 307-324, 2013.

DOS SANTOS, Anderson Silveira; LEHMANN, Wagner Walter; GRETTER, Elton Giovani. A gestáo da tecnologia da informação nas serventias extrajudiciais. Maiêutica-Cursos de Gestão, v. 1, n. 1, 2014.

GOEKEN, M.; ALTER, S. IT governance frameworks as methods. ICEIS - International Conference on Enterprise Information Systems. Frankfurt, Alemanha, 2008

HARDY, Gary. Using IT governance and COBIT to deliver value with IT and respond to legal, regulatory and compliance challenges. Information Security Technical Report Journal - ISSN: 1363-4127, v.11, p.55-66, 2006. 
ITGI. COBIT 5.0. Rolling Medaws: ITGI, 2012.

ITGI; OGC. Aligning COBIT 4.1, ITIL V3 and ISO/IEC 27002 for business benefit. USA, 2008.

ISACA - Information Systems Audit and Control Assossiation. Disponível em: http:// www.isaca.org/cobit. Acesso em: 19 de Março de 2014.

LAHTI, Christian B.; PETERSON, R. Sarbanes-Oxley IT Compliance Using COBIT and Open Source Tools. Elsevier: EUA, 2005.

PORTER, Michael E.; MILLAR, Vitor E. Como a informaçáo lhe proporciona vantagem competitiva. In: McGOWAN, William G. Revolução em tempo real: gerenciando a tecnologia da informação. Rio de Janeiro: Campus, 1997.

PORTER, Michael E. Competitive Advantage: Creating and Sustaining Superior Performance. Nova York, EUA: The Free Press, 1998.

ROWLANDS, Bruce; HAES, Steven De; GREMBERGEN, Wim Van. Exploring and Developing an IT Governance Culture Framework. IS Governance conference proceedings, 2014.

SARTURI, Márcia Campos; COSTA, Alexandre Marino. A gestáo estratégica de pessoas no processo de reorganizaçáo das atividades do Núcleo de Serventias Extrajudiciais da Corregedoria-Geral da Justiça de Santa Catarina. O judiciário catarinense na perspectiva dos seus servidores, vol. 3. Funjab, 2012.

SERBENA, Cesar Antonio. Interfaces atuais entre a e-justiça e a q-justiça no Brasil. Revista de Sociologia e Política, v. 21, n. 45, p. 47-56, 2013.

STEENBERGEN, M. V.; BERG, M. V. D.; BRINKKEMPER, S. An Instrument for the Development of the Enterprise Architecture Practice. IECS - International Conference on Enterprise Information Systems. p. 14-22, Portugal, 2007. 